\title{
An Economic Profile of the Charter Fishing Fleet in California
}

\author{
JAMES HILGER and SABRINA LOVELL
}

\section{Charter Fishing in California}

During 2012, anglers in California took over 544,000 saltwater fishing trips aboard charter or party boats, also known as commercial passenger fishing vessels (CPFV), and spent $\$ 120$ million on charter trip-related expenditures in the state (NMFS, 2014). Charter anglers in California can choose from a large selection of different trips. In Southern California, anglers can take half-day or full-day trips targeting species such as yellowfin tuna, Thunnus albacares; albacore tuna, Thunnus alalunga; dolphinfish, Coryphaena hippurus; and yellowtail, Seriola lalandi dorsalis. Or they may choose overnight or longer trips further off the coast targeting Pacific bluefin tuna, Thunnus orientalis.

In the San Francisco area and north

James Hilger, corresponding author, (James.Hilger@noaa.gov) is with the Fisheries Resource Division, Southwest Fisheries Science Center, National Marine Fisheries Service, NOAA, 8901 La Jolla Shores Drive, La Jolla, CA 90237. Sabrina Lovell is with the Office of Science and Technology, National Marine Fisheries Service, NOAA, 1315 East-West Highway, Silver Spring, MD 20910. This article and its findings do not necessarily reflect the views of the Department of Commerce, the National Oceanic and Atmospheric Administration, or the National Marine Fisheries Service.

doi: https://doi.org/10.7755/MFR.79.3-4.3 to the Oregon border, charter vessels take anglers out for Chinook salmon, Oncorhynchus tshawytscha. Throughout the state, anglers also target lingcod, Ophiodon elongates; vermillion rockfish, Sebastes miniatus; bocaccio, S. paucispinis; copper rockfish, $S$. caurinus; and yellowtail rockfish, S. flavidus. To better understand the economic sustainability of the industry and the financial situation for charter operators and crew, a survey focused on the 2012 season was administered in 2013 by the National Marine Fisheries Service's (NMFS) Southwest Fisheries Science Center (SWFSC) in La Jolla, Calif.

The survey is part of a series of national studies conducted regionally by NMFS on the recreational for-hire industry (e.g., charter and party boats) about every 5 years on a rotating basis. The Magnuson-Stevens Act, Executive Order 12866, and other federal regulations require NMFS to conduct economic analysis of the impacts of its management actions. The data collected in these surveys are used in the estimation of the economic contributions of the for-hire fleet to the local and regional economies and can be used to estimate the economic impacts of changes in the fishery.

These changes may include fishing regulations, such the establishment of marine protected areas which decrease available fishing grounds, and exogenous shocks to the industry such as rising costs associated with fishing and the effects of environmental changes on fishery stocks. The last survey of the CPFV fleet in California was conducted in 2000. ${ }^{1}$ Given significant changes in the economy and California fisheries in the intervening years, an updated survey was needed to understand current economic conditions in the industry and the issues affecting it throughout the state.

\section{Survey Methodology and Data Collection}

The 2013 California survey was designed to collect information on 2012 cost and earnings data for each fishing business and closely followed the format and methods from recent for-hire surveys conducted or supported by NMFS in the northeast (Steinback and Brinson $^{2}$ ), southeast (Liese and Carter,

${ }^{1}$ West Coast Charter Boat Survey Summary Report, 2000. 2004. Unpublished report, Pac. States Mar. Fish. Comm., Econ. Data Prog., Spokane, Wash. (online at http://www.psmfc. org/efin).

${ }^{2}$ Steinback, S., and A. Brinson. 2013. The economics of the recreational for-hire fishing industry in the northeast United States. U.S. Dep. Commer., NOAA, Natl. Mar. Fish. Serv., North-
ABSTRACT-Charter fishing off the California coast has long been a popular recreational activity for both California residents and tourists alike. With its long coastline, mild climate, and productive offshore waters, anglers have a myriad of year-round opportunities to catch a wide variety of species. To better understand the economic structure and performance of the industry, the NMFS Southwest Fisheries Science Cen- ter conducted a survey on key economic performance measures related to profitability, productivity, demographics, and challenges facing the industry for the 2012 season. The survey was administered in 2013. This paper provides an updated economic profile of the charter industry in California that can be used in analyses of future fisheries policy actions. It also presents the results for both small and large vessels, with large vessels defined as $15.24 \mathrm{~m}$ (50 ft) or longer. Survey findings include that revenues net of cost average \$42,033 per vessel in California, and that over $70 \%$ of owners are primary captains of at least one vessel. When asked about the factors affecting their business and industry, $71 \%$ of owners responded that fishery regulations were very challenging, while $36 \%$ responded that environmental conditions were very challenging. 
Table 1.-Surveys administered and completed by vessel size and location.

\begin{tabular}{lccccc}
\hline Category & $\begin{array}{c}\text { Total no. of active } \\
\text { charter businesses }\end{array}$ & $\begin{array}{c}\text { Surveys } \\
\text { administered }\end{array}$ & $\begin{array}{c}\text { Completed } \\
\text { surveys }\end{array}$ & $\begin{array}{c}\% \text { complete of } \\
\text { total businesses }\end{array}$ & $\begin{array}{c}\% \text { complete of } \\
\text { administered }\end{array}$ \\
\hline North large & 19 & 18 & 17 & $89 \%$ & $94 \%$ \\
North small & 77 & 18 & 16 & $21 \%$ & $89 \%$ \\
South large & 108 & 65 & 55 & $51 \%$ & $85 \%$ \\
South small & $\underline{60}$ & $\underline{22}$ & $\underline{15}$ & $\underline{25 \%}$ & $\underline{68 \%}$ \\
Total vessels & $\mathbf{1 2 3}$ & & & & \\
\hline
\end{tabular}

2011; Savolainen et al., 2011; Holland et al. ${ }^{3}$ ), Pacific Northwest (Leonard, 2016), and Pacific islands (Hospital and Beavers ${ }^{4}$ ). Hutt and Silva (2015) conducted a similar survey focused on for-hire vessels targeting Atlantic highly migratory species.

Many of these surveys have demonstrated that in-person interviews result in more accurate data. With that in mind, the survey sampling in California was divided into two phases consisting of in-person interviews in Phase 1, and a multi-mode design for Phase 2 with in-person, telephone, and mail-in options. This two-phase approach was thought to both maximize response rates and data quality. Although in-person interviews often result in better data, response rates may be lower due to scheduling difficulties. A mixed-mode design offers more scheduling flexibility and therefore a potentially higher response rate.

The survey was pre-tested using a pilot study of a small number of CPFV owner/operators in San Diego county, focused on the 2011 season, and was administered in 2012 (Hanan and $\operatorname{Hanan}^{5}$ ). Based on the pilot study, the 2012 survey questionnaire was organized into sections on industry participation, annual business based

east Fish. Sci. Cent. Ref. Doc. 13-03, 49 p. (online at https://www.nefsc.noaa.gov/publications/ crd/crd1303/crd1303.pdf).

${ }^{3}$ Holland, S., C. Oh, S. Larkin, and A. Hodges. 2012. The operations and economics of the forhire fishing fleets of the south Atlantic states and the Atlantic coast of Florida. Univ. Fla. contr. rep. prep. for NMFS Southeast Fish. Sci. Cent., Miami, Fla.

${ }^{4}$ Hospital, J., and C. Beavers. Hawaii charter fishing cost-earnings survey, 2012. Unpubl. rep., for Pac. Isl. Fish. Sci. Cent., Honolulu, Hawaii.

${ }^{5}$ Hanan, D., and Z. Hanan. 2012. West coast charter boat cost-earning pilot survey for FY 2011. Rep. submitted to NMFS Southwest Fish. Sci. Cent., La Jolla, Calif. expenditures, vessel characteristics, annual vessel based expenditures, annual vessel based fishing operations revenue, annual vessel based non-fishing operations revenue, individual trip type expenses and revenues, owner opinion, and business structure and outlook.

The California Department of Fish and Wildlife (CDFW) provided NMFS with a list of all charter vessels registered in the state during 2012 and conwere 339 registered vessels reported in the 2012 CPFV fishing logs. Of these, 324 vessels reported carrying at least one passenger on a sportfishing trip. Removal of vessels with no available contact information reduced the number of active vessels to 264 (Table 1). These 264 vessels were stratified into four groups based on a combination of geographic area (North and South) and vessel size.

The South area included San Diego, Orange, Los Angeles, Ventura, and Santa Barbara counties. The North area included all other coastal counties north of Santa Barbara. To explore the heterogeneity across vessel size classes, vessels $50 \mathrm{ft}(15.24 \mathrm{~m})$ or larger were classified as "Large" and vessels less than $50 \mathrm{ft}$ as "Small." The CPFV fleet was then divided into four groups: North Large, South Large, North Small, and South Small. We limit this report to differences between large and small vessel categories. Future reports will provide details on the North/South subcategories.

The target population of the survey was charter businesses, rather than individual vessels. Each business may own one or more vessels. In Phase 1, 148 owners of a charter business were selected for in-person interviews from the list using stratified random samtact information for the owner. There pling across the four location/size categories. In Phase 2, the remaining 116 owners were selected for either in-person interviews, phone interviews, or a mail survey (Hanan et al. ${ }^{6}$ ).

Table 1 shows the total number of charter businesses, the number of surveys administered, and completion rates for both phases. Inaccurate contact information, refusals, and inability to reach an owner after multiple attempts reduced the number of owners scheduled for the survey, both for the total fleet and stratified by vessel location and vessel size category. The total number of surveys administered in person, over the phone, or by mail was 123. Surveys with at least $95 \%$ of the questions answered were considered complete. Of those business owners who responded to the survey, $84 \%$ resulted in what was considered a completed survey. Of all the owners with active CPFV operations during 2012, $39 \%$ participated and completed the survey. Stratified by size of vessel, response rates were higher for large vessel businesses (57\%) than small vessel businesses (23\%). Survey summary statistics were estimated in STATA/ MP (version 14.1, 2015) ${ }^{7}$ using the subset of observations that were complete for each question.

\section{CPFV Fleet Profile}

The first panel of Table 2 provides the characteristics of CPFV owners as to their involvement in the fishery. Across all vessels, owners had an average of 33 years of experience with the industry in some capacity (e.g., deck hand, captain, cook). Owners of small vessels had on average 22 years of experience, compared to 39 years of experience for large vessel owners. Seventy-two percent of owners reported that they were also the primary captains of a CPFV. For owners of small vessels, $90 \%$ were also cap-

${ }^{6}$ Hanan, D., Z. Hanan, and J. Sweeney. 2014. California commercial passenger fishing vessel (CPFV) cost-earnings survey for 2012. Rep. submitted to NMFS Southwest Fish. Sci. Cent., La Jolla, Calif.

${ }^{7}$ Mention of trade names or commercial firms does not imply endorsement by the National Marine Fisheries Service, NOAA. 
Table 2.-Characteristics of owners and vessels by size of vessel.

\begin{tabular}{|c|c|c|c|c|c|c|c|c|c|c|}
\hline \multirow[b]{2}{*}{ Variable } & \multicolumn{3}{|c|}{ Small } & \multicolumn{3}{|c|}{ Large } & \multirow[b]{2}{*}{ Diff $^{1}$} & \multicolumn{3}{|c|}{ Total } \\
\hline & $N$ & Mean & Std. dev. & $N$ & Mean & Std. dev. & & $N$ & Mean & Std. dev. \\
\hline \multicolumn{11}{|l|}{ Owner demographics } \\
\hline Years' experience in CPFV industry & 31 & 22.1 & 16.6 & 72 & 38.7 & 12.0 & $\star \star \star ~$ & 103 & 33.7 & 15.5 \\
\hline$\%$ primary captain on any vessel & 31 & $90.3 \%$ & $30.1 \%$ & 72 & $63.9 \%$ & $48.4 \%$ & 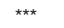 & 103 & $71.8 \%$ & $45.2 \%$ \\
\hline No. of vessels owned & 31 & 1.4 & 0.9 & 72 & 2.3 & 1.8 & 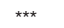 & 103 & 2.0 & 1.6 \\
\hline$\%$ of income from CPFV operations & 26 & $23.1 \%$ & $18.7 \%$ & 47 & $49.0 \%$ & $29.2 \%$ & $\star \star \star ~$ & 73 & $39.9 \%$ & $28.7 \%$ \\
\hline \multicolumn{11}{|l|}{ Vessel characteristics } \\
\hline Gross tonnage & 30 & 14.2 & 11.7 & 72 & 58.0 & 25.5 & 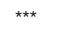 & 102 & 45.1 & 29.9 \\
\hline Length $(\mathrm{ft})$ & 31 & 33.7 & 8.4 & 72 & 65.0 & 13.2 & $\star \star \star ~$ & 103 & 55.5 & 18.7 \\
\hline Year built & 31 & 1987 & 14.5 & 72 & 1973 & 13.4 & $\star \star \star ~$ & 103 & 1977 & 14.9 \\
\hline Maximum crew & 30 & 1.9 & 0.9 & 72 & 3.6 & 3.6 & 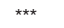 & 102 & 3.1 & 3.1 \\
\hline Maximum no. of passengers & 31 & 11.3 & 11.2 & 72 & 60.8 & 35.1 & 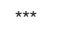 & 103 & 45.9 & 37.6 \\
\hline Maximum overnight passengers & 11 & 5.7 & 3.8 & 36 & 30.5 & 14.7 & $\star \star \star$ & 47 & 24.7 & 16.7 \\
\hline
\end{tabular}

${ }^{1}$ Significance of difference between mean of small and large vessel: ${ }^{\star} p<0.1,{ }^{\star \star} p<0.05,{ }^{\star \star \star} p<0.01$.

Table 3.-Average revenues by vessel size. ${ }^{1}$

\begin{tabular}{|c|c|c|c|c|c|c|c|c|c|c|}
\hline \multirow[b]{2}{*}{ Variable } & \multicolumn{3}{|c|}{ Small } & \multicolumn{3}{|c|}{ Large } & \multirow[b]{2}{*}{ Diff $^{1}$} & \multicolumn{3}{|c|}{ Total } \\
\hline & $N$ & Mean & Std. dev. & $N$ & Mean & Std. dev. & & $N$ & Mean & Std. dev. \\
\hline Ticket sales and related fees & 31 & $\$ 77,271$ & $\$ 118,520$ & 72 & $\$ 343,120$ & $\$ 320,629$ & $\star \star \star$ & 103 & $\$ 263,107$ & $\$ 301,173$ \\
\hline Food and beverage sales & 31 & $\$ 226$ & $\$ 1,257$ & 72 & $\$ 9,863$ & $\$ 23,994$ & ** & 103 & $\$ 6,962$ & $\$ 20,517$ \\
\hline Filet charges to vessel & 31 & $\$ 97$ & $\$ 539$ & 71 & $\$ 371$ & $\$ 2,257$ & & 102 & $\$ 287$ & $\$ 1,906$ \\
\hline Souvenirs & 31 & $\$ 79$ & $\$ 366$ & 70 & $\$ 127$ & $\$ 419$ & & 101 & $\$ 112$ & $\$ 402$ \\
\hline CDFW angler license commissions & 31 & $\$ 261$ & $\$ 1,455$ & 71 & $\$ 0$ & $\$ 0$ & & 102 & $\$ 79$ & $\$ 802$ \\
\hline Average subtotal: Recreational fishing & 31 & $\overline{\$ 77,934}$ & $\$ 118,567$ & $\overline{72}$ & $\$ 353,472$ & $\$ 326,805$ & 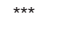 & $\overline{103}$ & $\overline{\$ 270,543}$ & $\$ 307,582$ \\
\hline Nonfishing recreation & 31 & $\$ 3,117$ & $\$ 12,690$ & 70 & $\$ 79,030$ & $\$ 156,384$ & 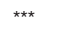 & 101 & $\$ 55,730$ & $\$ 134,763$ \\
\hline Commercial fishing & 31 & $\$ 14,880$ & $\$ 59,339$ & 70 & $\$ 3,645$ & $\$ 20,175$ & & 101 & $\$ 7,093$ & $\$ 36,936$ \\
\hline Nonrecreational charter & 31 & $\$ 232$ & $\$ 533$ & 68 & $\$ 7,809$ & $\$ 26,451$ & & 99 & $\$ 5,437$ & $\$ 22,156$ \\
\hline Lodging & 31 & $\$ 0$ & $\$ 0$ & 70 & $\$ 0$ & $\$ 0$ & & 101 & $\$ 0$ & $\$ 0$ \\
\hline Equipment rental & 31 & $\$ 0$ & $\$ 0$ & 70 & $\$ 0$ & $\$ 0$ & & $\underline{101}$ & $\$ 0$ & $\$ 0$ \\
\hline Average subtotal: Nonrecreational fishing & 31 & $\$ 18,230$ & $\$ 59,951$ & $\overline{72}$ & $\$ 87,753$ & $\$ 159,574$ & ** & 103 & $\$ 66,829$ & $\$ 140,744$ \\
\hline Average total revenues & 31 & $\$ 96,163$ & $\$ 132,519$ & 72 & $\$ 441,225$ & $\$ 369,858$ & 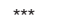 & 103 & $\$ 337,371$ & $\$ 354,515$ \\
\hline
\end{tabular}

${ }^{1}$ Average subtotal and total calculations are the average of individual vessel totals summed over all categories and may not equal the sum of the average per category. This is due to the exclusion of missing values in the calculation of category averages, and the implicit impact of the missing values being treated as zeros in the calculation of individual vessel totals. ${ }^{2}$ Significance of difference between mean of small and large vessel: ${ }^{*} p<0.1,{ }^{\star} p<0.05,{ }^{* \star} p<0.01$.

tains. The percentage was much lower for large vessel owners, where $64 \%$ reported that they were also captains. The average number of vessels owned by a single owner was two (2.0) for all respondents with slightly lower averages for small vessel owners (1.4) compared to large vessel owners (2.3).

Across all vessels, owners received $40 \%$ of their income from CPFV operations on average. Owners of small vessels received $23 \%$ of their income from CPFV operations, whereas owners of large vessels received $49 \%$. Table 2 also provides the results of $t-$ tests on the differences in the means between large and small vessels for each of the owner characteristics. The results indicate statistically significant differences in all of the characteristics.

The second panel of Table 2 reports summary statistics for vessel characteristics. The average CPFV has a gross tonnage of 45 (40.8 t), a length of 56 feet $(16.9 \mathrm{~m})$, and was built in 1977. Small vessels average a gross tonnage of $14(12.7 \mathrm{t})$ and a length of 34 feet $(10.4 \mathrm{~m})$. Large vessels averaged 58 tons $(52.6 \mathrm{t})$ and 65 feet (19.8 $\mathrm{m})$. Small vessels are newer by 14 years on average, having been built in 1987, compared to large vessels that were built in 1973 .

The maximum number of crew was 3 for all vessels and the maximum number of passengers was 46. Smaller vessels have an average crew size of 2 and hold a maximum of 11 passengers. Larger vessels have a crew size of 4 on average and hold a maximum of 61 passengers. Overnight trips are offered by a subset of 47 out of 103 vessels from both size classes. On average these vessels have an overnight capacity of 25 passengers. Eleven (11) out of 31 of the small vessels offer overnight trips with an average overnight capacity of 6 passengers. Thirty-six (36) of the 72 large vessels offer overnight trips with an average overnight capacity of 31 passengers. All vessel characteristics showed statistically significant differences between the means of large and small vessels.

\section{Costs and Earnings}

Table 3 reports the average revenues for vessels in the CPFV fleet. Average revenues were calculated at the CPFV level, rather than owner level. The average total revenues across all categories were $\$ 337,371$ for all vessels, $\$ 96,163$ for small vessels, and $\$ 441,225$ for large vessels. ${ }^{8}$ Table 3 also shows revenues stratified by

\footnotetext{
${ }^{8}$ Average total calculations are the average of individual vessel totals summed over all categories and may not equal the sum of the average per category. This is due to the exclusion of missing values in the calculation of category averages, and the implicit impact of the missing values being treated as zeros in the calculation of individual vessel totals.
} 
Table 4.-Average expenditures and net revenue by vessel size. ${ }^{1}$

\begin{tabular}{|c|c|c|c|c|c|c|c|c|c|c|}
\hline \multirow[b]{2}{*}{ Variable } & \multicolumn{3}{|c|}{ Small } & \multicolumn{3}{|c|}{ Large } & \multirow[b]{2}{*}{ Diff $^{2}$} & \multicolumn{3}{|c|}{ Total } \\
\hline & $N$ & Mean & Std. dev. & $N$ & Mean & Std. dev. & & $N$ & Mean & Std. dev. \\
\hline Payroll for skipper and crew & 31 & $\$ 10,677$ & $\$ 11,383$ & 70 & $\$ 94,939$ & $\$ 82,432$ & 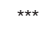 & 101 & $\$ 69,076$ & $\$ 79,076$ \\
\hline Vessel fuel costs & 31 & $\$ 17,520$ & $\$ 37,540$ & 68 & $\$ 86,790$ & $\$ 106,489$ & $\star \star \star \star$ & 99 & $\$ 65,100$ & $\$ 96,056$ \\
\hline Bait costs & 30 & $\$ 3,910$ & $\$ 5,987$ & 72 & $\$ 34,047$ & $\$ 27,745$ & $\star \star \star$ & 102 & $\$ 25,183$ & $\$ 27,237$ \\
\hline Booking fees & 31 & $\$ 6,292$ & $\$ 13,463$ & 72 & $\$ 27,915$ & $\$ 27,175$ & 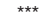 & 103 & $\$ 21,407$ & $\$ 25,821$ \\
\hline \multicolumn{11}{|l|}{ Equipment purchases, repair } \\
\hline and maintenance & 31 & $\$ 8,369$ & $\$ 13,442$ & 72 & $\$ 25,487$ & $\$ 22,650$ & 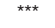 & 103 & $\$ 20,335$ & $\$ 21,737$ \\
\hline Food and drink costs & 31 & $\$ 427$ & $\$ 1,282$ & 67 & $\$ 21,972$ & $\$ 44,701$ & $\star \star \star$ & 98 & $\$ 15,157$ & $\$ 38,230$ \\
\hline Moorage & 31 & $\$ 4,613$ & $\$ 4,076$ & 71 & $\$ 13,241$ & $\$ 16,487$ & *** & 102 & $\$ 10,619$ & $\$ 14,465$ \\
\hline \multicolumn{11}{|l|}{ Foreign taxes, gov't. fees, and } \\
\hline fishing licenses & 31 & $\$ 185$ & $\$ 604$ & 71 & $\$ 7,207$ & $\$ 18,388$ & $\star \star$ & 102 & $\$ 5,073$ & $\$ 15,652$ \\
\hline Annual principal payment on vessels & 30 & $\$ 299$ & $\$ 932$ & 68 & $\$ 6,542$ & $\$ 15,194$ & ** & 98 & $\$ 4,631$ & $\$ 12,965$ \\
\hline U.S. taxes, gov't. fees, and vessel permits & 30 & $\$ 3,406$ & $\$ 4,778$ & 72 & $\$ 4,969$ & $\$ 9,268$ & & 102 & $\$ 4,509$ & $\$ 8,213$ \\
\hline Haul out costs & 29 & $\$ 648$ & $\$ 1,397$ & 68 & $\$ 5,697$ & $\$ 7,823$ & $\star \star \star$ & 97 & $\$ 4,188$ & $\$ 6,978$ \\
\hline Annual interest payment on vessels & 30 & $\$ 128$ & $\$ 479$ & 67 & $\$ 3,251$ & $\$ 8,439$ & ** & 97 & $\$ 2,285$ & $\$ 7,151$ \\
\hline Industry association fees/memberships & 30 & $\$ 334$ & $\$ 577$ & 71 & $\$ 2,692$ & $\$ 3,113$ & $\star \star \star$ & 101 & $\$ 1,992$ & $\$ 2,838$ \\
\hline Ice (purchased dockside) & 31 & $\$ 262$ & $\$ 562$ & 71 & $\$ 348$ & $\$ 799$ & & 102 & $\$ 322$ & $\$ 733$ \\
\hline Average subtotal: Vessel expenditures & 31 & $\$ 56,768$ & $\$ 56,291$ & 72 & $\$ 324,880$ & $\$ 293,795$ & 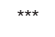 & 103 & $\$ 244,186$ & $\$ 276,200$ \\
\hline Payroll of nonvessel personnel & 31 & $\$ 1,048$ & $\$ 3,535$ & 71 & $\$ 17,527$ & $\$ 27,378$ & 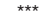 & 102 & $\$ 12,519$ & $\$ 24,109$ \\
\hline Insurance & 31 & $\$ 4,872$ & $\$ 6,100$ & 72 & $\$ 14,380$ & $\$ 7,167$ & 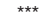 & 103 & $\$ 11,518$ & $\$ 8,118$ \\
\hline Rent paid on office space used for business & 30 & $\$ 2,668$ & $\$ 4,610$ & 69 & $\$ 13,187$ & $\$ 27,100$ & ** & 99 & $\$ 10,000$ & $\$ 23,227$ \\
\hline Advertising services or charges & 31 & $\$ 2,808$ & $\$ 4,059$ & 71 & $\$ 9,584$ & $\$ 12,688$ & 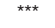 & 102 & $\$ 7,525$ & $\$ 11,238$ \\
\hline Professional services (legal, accounting, etc.) & 31 & $\$ 1,102$ & $\$ 2,276$ & 72 & $\$ 6,016$ & $\$ 7,611$ & $\star \star \star$ & 103 & $\$ 4,537$ & $\$ 6,854$ \\
\hline Telephone and other communications & 31 & $\$ 2,320$ & $\$ 4,289$ & 71 & $\$ 4,001$ & $\$ 4,628$ & * & 102 & $\$ 3,490$ & $\$ 4,573$ \\
\hline \multicolumn{11}{|l|}{ Lease or loan payments for business } \\
\hline motor vehicles & 31 & $\$ 368$ & $\$ 881$ & 71 & $\$ 3,003$ & $\$ 10,472$ & & 102 & $\$ 2,202$ & $\$ 8,816$ \\
\hline Average subtotal: Business expenditures & 31 & $\$ 15,099$ & $\$ 16,046$ & $\overline{72}$ & $\$ 66,675$ & $\$ 67,346$ & *** & $\overline{103}$ & $\$ 51,152$ & $\$ 61,626$ \\
\hline Average total expenditures & 31 & $\$ 71,866$ & $\$ 62,986$ & 72 & $\$ 391,555$ & $\$ 330,477$ & 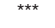 & 103 & $\$ 295,338$ & $\$ 314,486$ \\
\hline Average vessel net revenue & 31 & $\$ 24,297$ & $\$ 134,123$ & 72 & $\$ 49,670$ & $\$ 200,463$ & & 103 & $\$ 42,033$ & $\$ 182,757$ \\
\hline
\end{tabular}

recreational fishing based revenues and nonrecreational fishing based revenues.

Across all vessels, total recreational fishing based revenues average $\$ 270,543$ and total nonrecreational fishing based revenues average $\$ 66,829$. For small vessels, the average of total revenues across recreational fishing and nonrecreational fishing revenue categories are $\$ 77,934$ and $\$ 18,230$. For large vessels, the average of total revenues across recreational fishing and nonrecreational fishing revenues are $\$ 353,472$ and $\$ 87,753$. The following paragraph provides a breakout of revenues by category.

Ticket sales and related fees, such as fuel surcharges, rod rentals, gunny sack, and bunk surcharges, were the largest revenue category for all vessels regardless of size of the CPFV. On average, a vessel collected $\$ 263,107$ in ticket sales and related fees, with small vessels collecting \$77,271, and large vessels collecting $\$ 343,120$. Across all vessels, nonfishing recreational charters, commercial fishing activities, and food and beverage sales were the 2nd, 3rd, and 4th largest revenue streams with revenues of $\$ 55,730, \$ 7,093$, and $\$ 6,962$, respectively.

Based on size of the vessel, there is a difference in the next highest revenue-generating activity. Smaller vessels generate $\$ 14,880$ in commercial fishing related revenues, followed by $\$ 3,117$ in nonfishing recreational trips. While for large vessels, nonfishing recreational trips account for $\$ 79,030$ in average revenues, followed by food and beverage sales of $\$ 9,863$. Small vessels report \$226 in food and beverage sales, and large vessels report $\$ 3,645$ in commercial fishing activities.

Nonrecreational and nonfishing charter trips account for $\$ 5,437$ of revenues across all vessels; with an average of $\$ 232$ in revenues for small vessels, and $\$ 7,809$ in revenues for large vessels. Other revenue sources include filet charges, sales of souvenirs, and commissions on angler licenses. These categories accounted for an average of $\$ 287, \$ 112$, and $\$ 79$ in revenues, respectively across all vessels. For small vessels the average revenues were $\$ 97$,
\$79, and \$261, respectively, while for large vessels average revenues were $\$ 371, \$ 127$, and \$0, respectively. None of the CPFV's reported revenues from lodging or equipment rentals.

Expenditures are reported in Table 4 after allocating expenditures to the vessel level. In cases where business expenses were split between multiple vessels, an even share of the expenses were attributed to each vessel. Table 4 reports expenditures by individual expenditure category; individual categories are organized into both vessel expenditures (top panel) and business expenditures (bottom panel). Total average expenditures were $\$ 295,338$ for all vessels, $\$ 391,555$ for large vessels, and $\$ 71,866$ for small vessels.

Expenditures on payroll for the skipper/captain and the crew was the largest expenditure category on average for all vessels and for large vessels. For all vessels, payroll was $\$ 69,076$ on average; for large vessels it was $\$ 94,939$. For small vessels, average payroll expenditures were $\$ 10,677$. The second largest category of expenditures for all vessels was for fuel costs, averaging 
Table 5. - Average vessel and trip characteristics by trip length and vessel size. ${ }^{1}$

\begin{tabular}{|c|c|c|c|c|c|c|c|c|c|c|}
\hline \multirow[b]{2}{*}{ Variable } & \multicolumn{3}{|c|}{ Small } & \multicolumn{3}{|c|}{ Large } & \multirow[b]{2}{*}{ Diff $^{2}$} & \multicolumn{3}{|c|}{ Total } \\
\hline & $N$ & Mean & Std. dev. & $N$ & Mean & Std. dev. & & $N$ & Mean & Std. dev. \\
\hline Annual angler days-partial day & 14 & 260 & 277 & 28 & 5,369 & 6,133 & 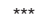 & 42 & 3,666 & 5,544 \\
\hline Annual angler days-full day & 23 & 572 & 801 & 43 & 2,800 & 2,195 & $* \star \star$ & 66 & 2,024 & 2,115 \\
\hline Annual angler days-overnight & 3 & - & - & 22 & 1,254 & 1,518 & - & 25 & - & - \\
\hline Annual angler days-long distance & 0 & $\mathrm{n} / \mathrm{a}$ & $\mathrm{n} / \mathrm{a}$ & 16 & 3,197 & 2,350 & $\mathrm{n} / \mathrm{a}$ & 16 & 3,197 & 2,350 \\
\hline$\%$ of angler days-partial day & 14 & $69 \%$ & $36 \%$ & 28 & $57 \%$ & $32 \%$ & & 42 & $61 \%$ & $33 \%$ \\
\hline$\%$ of angler days-full day & 23 & $76 \%$ & $35 \%$ & 43 & $67 \%$ & $34 \%$ & & 66 & $70 \%$ & $35 \%$ \\
\hline$\%$ of angler days-overnight & 3 & - & - & 22 & $52 \%$ & $44 \%$ & - & 25 & - & - \\
\hline$\%$ of angler days-long distance & 0 & $\mathrm{n} / \mathrm{a}$ & $\mathrm{n} / \mathrm{a}$ & 16 & $79 \%$ & $30 \%$ & $\mathrm{n} / \mathrm{a}$ & 16 & $79 \%$ & $30 \%$ \\
\hline Length of trip in hours-partial day & 14 & 4.9 & 1.0 & 28 & 6.0 & 1.5 & ** & 42 & 5.6 & 1.4 \\
\hline Length of trip in hours-full day & 23 & 8.8 & 1.5 & 43 & 10.3 & 1.8 & 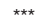 & 66 & 9.8 & 1.8 \\
\hline Length of trip in hours-overnight ${ }^{3}$ & 3 & - & - & 22 & 24.0 & 6.5 & - & 25 & - & - \\
\hline Length of trip in hour-long distance & 0 & $\mathrm{n} / \mathrm{a}$ & $\mathrm{n} / \mathrm{a}$ & 16 & 102 & 54 & $\mathrm{n} / \mathrm{a}$ & 16 & 102 & 54 \\
\hline
\end{tabular}

${ }^{1}$ Average statistics are conditional on the vessel providing the respective trip length. Zero values are excluded from calculations.

2Significance of difference between mean of small and large vessel: * $p<0.1,{ }^{\star \star} p<0.05,{ }^{\star \star \star} p<0.01$.

${ }^{3}$ Averages not shown to maintain confidentiality when three or fewer responses are provided.

$\$ 65,100$ per vessel. For small vessels, fuel costs, at $\$ 17,520$, were higher than payroll costs and the largest expenditure category. For large vessels fuel costs were the second highest expense at $\$ 86,790$. For small vessels, however, fuel costs were the highest average expenditure $(\$ 17,520)$.

Bait expenditures were the third highest expenditure category across all vessels and for large vessels, with an average of $\$ 25,183$ and $\$ 34,047$, respectively. Small vessels report average bait expenditures of $\$ 3,910$. On smaller vessels, the third highest type of expenditure was equipment purchases, repair, and maintenance averaging $\$ 8,369$. For all vessels, the average total for vessel expenditures was $\$ 244,186$. For small vessels, the average total for vessel expenditures was $\$ 56,768$; large vessels averaged $\$ 324,880$.

In terms of business expenditures, the highest expenditure for all vessels and for large vessels was payroll of nonvessel personnel; \$12,519 and $\$ 17,527$, respectively. Insurance was the second highest business expense. For all vessels, insurance expenditures averaged $\$ 11,518$. For large vessels, average insurance expenditures were $\$ 14,380$. For small vessels, insurance was the number one business expense, averaging $\$ 4,872$. Rent paid on office space $(\$ 10,000)$ and advertising services $(\$ 7,525)$ were the third and fourth highest expenditures for all vessels. For all vessels, average business expendi- tures were $\$ 51,152$. For large vessels, the average was $\$ 66,675$, and for small vessels, the average was $\$ 15,099$.

The average net vessel revenue across all vessels was $\$ 42,033$. Small vessels had average net revenues of $\$ 24,297$. On average, net revenues for large vessels were $\$ 49,670$. Positive average net revenues across the fleet and for both vessel size stratifications indicate that, on average, the fleet is profitable. However, the large standard deviation statistics across fleet-wide, small vessel, and large vessel net revenue statistics indicate that many individual boats have negative net-revenues.

\section{Average Trip Characteristics}

The survey asked owners a series of questions regarding the characteristics of an average trip for different trip lengths that are common in the CPFV fleet. The trip length categories are partial-day (half-day and twilight trips), full-day (includes 3/4 day trips), overnight (includes day and a half trips), and long-distance (includes multi-day trips, and trips to Mexico and international waters). Stratified by trip length and size of vessel, Table 5 shows the average per vessel annual number of angler days, the average vessel percentage of angler days, and the average length of a trip in hours; all three statistics are conditional on the vessel providing the respective trip length. Results are broken out by vessel size categories (small, large, and all vessels). An angler day is measured as either a partial or full-day trip by one angler.

The first four rows of Table 5 report the average vessel annual number of angler days provided by trip length and the corresponding standard deviation; all statistics are conditional on the vessel having offered trips of the respective size class. For partial day trips, the average per vessel annual number of angler days was 3,666 for all vessels. Small vessels averaged 260 angler days and large vessels averaged 5,369 angler days on partial-day trips; the difference between small and large is statistically different at the $1 \%$ level.

On full-day trips, the average per vessel annual number of angler days was 2,024 angler days for all vessels. Small vessels averaged 572 angler days, and large vessels averaged 2,800 angler days on full-day trips; the difference between small and large is statistically different at the $1 \%$ level. For overnight trips, the average per vessel annual number of angler days was 1,245 for large vessels. Statistics for small and all vessels are not provided due to confidentially concerns. For long distance trips, the average per vessel annual number of angler days was 3,197 for large vessels; no long distance trips were reported by small vessels.

The second four rows of Table 5 report the average vessel percentage of angler days provided by trip length and the corresponding standard devia- 
tion; all statistics are conditional on the vessel having offered a trip of the respective size class. For partial day trips, the average per vessel percentage of angler days was $61 \%$ for all vessels. Small vessels averaged 69\% and large vessels averaged 57\%; the difference between small and large vessels is not considered to be statistically different at any conventional level. On full-day trips, the average per vessel percentage of angler days was 70\% for all vessels. Small vessels averaged $76 \%$ and large vessels averaged $67 \%$ for full day trips; the difference between small and large vessels is not considered to be statistically different at any conventional level. On overnight trips, the average per vessel percentage of angler days was $52 \%$ for large vessels. Statistics for small and all vessels are not provided due to confidentially concerns. For long distance trips, the average per vessel percentage of angler days was $79 \%$ for large vessels; no long distance trips were reported by small vessels.

The third four rows of Table 5 report the average vessel length of a trip in hours (h) by trip length and the corresponding standard deviation; all statistics are conditional on the vessel having offered a trip of the respective size class. For partial day trips, the average per vessel length of a trip was $5.6 \mathrm{~h}$ for all vessels. Small vessel trips averaged $4.9 \mathrm{~h}$, and large vessels averaged $6 \mathrm{~h}$ on partial-day trips; the difference between small and large is statistically different at the 5\% level. On full-day trips, the average per vessel length of a trip was $9.8 \mathrm{~h}$ for all vessels. Small vessel trips averaged $8.8 \mathrm{~h}$, and large vessels averaged 10.3 $\mathrm{h}$ for full day trips; the difference between small and large is statistically different at the 1\% level. For overnight trips, the average per vessel length of trip was $24 \mathrm{~h}$, or 1 day, for large vessels. Statistics for small and all vessels are not provided due to confidentially concerns. For long distance trips, the average per vessel length of trip was $102 \mathrm{~h}$, or over 4 days, for large vessels; no long distance trips were reported by small vessels.

Table 6.-Factors affecting CPFV businesses and the industry.

\begin{tabular}{|c|c|c|c|c|c|c|}
\hline \multirow[b]{2}{*}{ Item } & \multicolumn{6}{|c|}{ Percentage of owners answering } \\
\hline & $\begin{array}{c}\text { Very } \\
\text { challenging }\end{array}$ & $\begin{array}{l}\text { Somewhat } \\
\text { challenging }\end{array}$ & Neutral & $\begin{array}{l}\text { Somewhat } \\
\text { favorable }\end{array}$ & $\begin{array}{c}\text { Very } \\
\text { favorable }\end{array}$ & N \\
\hline \multicolumn{7}{|l|}{ Small vessel } \\
\hline Fishery regulations (including MPA's) & $65 \%$ & $13 \%$ & $13 \%$ & $3 \%$ & $6 \%$ & 31 \\
\hline Non-fishery gov't. regulations & $26 \%$ & $35 \%$ & $35 \%$ & $3 \%$ & $0 \%$ & 31 \\
\hline Environmental conditions & $35 \%$ & $39 \%$ & $23 \%$ & $3 \%$ & $0 \%$ & 31 \\
\hline Ocean and fish stock health & $39 \%$ & $23 \%$ & $10 \%$ & $19 \%$ & $10 \%$ & 31 \\
\hline \multicolumn{7}{|l|}{ Large vessel } \\
\hline Fishery regulations (including MPA's) & $73 \%$ & $17 \%$ & $6 \%$ & $4 \%$ & $0 \%$ & 71 \\
\hline Non-fishery gov't. regulations & $39 \%$ & $42 \%$ & $15 \%$ & $4 \%$ & $0 \%$ & 72 \\
\hline Environmental conditions & $37 \%$ & $28 \%$ & $34 \%$ & $1 \%$ & $0 \%$ & 71 \\
\hline Ocean and fish stock health & $21 \%$ & $29 \%$ & $18 \%$ & $12 \%$ & $21 \%$ & 68 \\
\hline \multicolumn{7}{|l|}{ Total } \\
\hline Fishery regulations (including MPA's) & $71 \%$ & $16 \%$ & $8 \%$ & $4 \%$ & $2 \%$ & 102 \\
\hline Non-fishery gov't. regulations & $35 \%$ & $40 \%$ & $21 \%$ & $4 \%$ & $0 \%$ & 103 \\
\hline Environmental conditions & $36 \%$ & $31 \%$ & $30 \%$ & $2 \%$ & $0 \%$ & 102 \\
\hline Ocean and fish stock health & $26 \%$ & $27 \%$ & $15 \%$ & $14 \%$ & $17 \%$ & 99 \\
\hline
\end{tabular}

Table 5 provides empirical support of the following insights. First, full day trips are the most commonly offered, regardless of vessel size class. Overall, 66 out of 103 vessels which completed the survey offered full day trips; corresponding figures for small and large vessels are 23 out of 33 , and 43 out of 72 , respectively. Partial day trips were the second most commonly offered, regardless of vessel size. For vessels that offered full-day trips, these trips made up the majority of their annual passenger loads. Over all vessels, full-day trips made up an average of $70 \%$ of vessel days for vessels that provided them; corresponding figures for small and large vessels are $76 \%$ and $67 \%$, respectively.

A second insight is that most vessels specialize in one primary trip length and then fill in their schedules with secondary trip length. Evidence of this can be seen in the high average and standard deviation percentages by trip length, and the spread of the number of vessels offering each trip length. A third insight is that there is consistency in the length of trips in hours as reported by vessels for each trip length category.

\section{Factors Affecting Business Operations}

To understand the factors impacting individual CPFV businesses and the industry overall, a series of short questions were asked about regulations, the environment, and a few broader economic issues. Respondents were asked to rate each issue as very challenging, somewhat challenging, neutral, somewhat favorable, or very favorable. For brevity, the issues that at least $50 \%$ of owners rated as very challenging or somewhat challenging are presented in Table $6 .{ }^{9}$

One of the issues that a majority of respondents rated as very challenging was "fishery regulations including marine protected areas (MPA's)." Overall, $71 \%$ of owners rated it as very challenging. For owners of large vessels, $73 \%$ rated it as very challenging and $17 \%$ as somewhat challenging. For small vessel owners, 65\% rated it as very challenging and $13 \%$ as somewhat challenging. Non-fishery government regulations were rated by only $35 \%$ of owners as very challenging, and by $40 \%$ as somewhat challenging; during the interviews some vessel owners noted that safety regulations were appreciated. Thirty-nine percent of large vessel owners replied that these regulations were very challenging compared to $26 \%$ of small vessel owners.

Environmental conditions were rated as very challenging by $36 \%$ of all vessel owners, $37 \%$ of large vessel owners, and $35 \%$ of small vessel owners.

${ }^{9}$ The results of other issues are available upon request from the NMFS Southwest Fish. Sci. Cent. 
Ocean and fish stock health concerned fewer of the large vessel owners, with $21 \%$ rating it as very challenging and $29 \%$ as somewhat challenging. For small vessel owners, the issue was a larger concern, with 39\% rating it as very challenging, compared to $23 \%$ who rated it as somewhat challenging.

\section{Discussion}

This paper presents results of a survey of CPFV businesses that asked questions about the 2012 fishing season. Updated information on the financial situation facing individual vessel owners and the industry overall is critical to understanding how current and future environmental conditions, economic trends, and fisheries regulations will impact the future sustainability of this important sector of the California economy. Response rates to the survey were comparable to other similar surveys around the country; the 2010 survey in the Northeast had an overall response rate of $48 \%$ (Steinback and Brinson $^{2}$ ); a 2012 survey in the Pacific Northwest had a $55 \%$ response rate $\left(\right.$ Leonard $\left.{ }^{10}\right)$. For large California charter vessels, the response rate in this survey was $57 \%$, however, the percentage was lower for the small vessels $(23 \%)$. The high level of outreach prior to the start of the survey appears to have positively affected willingness to participate.

Prior to the actual survey, SWFSC economists and the contractor met with many angling groups to discuss the upcoming survey, worked with angling associations to publicize it, and conducted a pilot study to get feedback on the questionnaire. Additionally, the use of in-person interviews resulted in a higher number of complete interviews than the other methods, with an $87 \%$ completion rate. Over-the-phone interviews had an $86 \%$ completion rate. In contrast, the mail-based surveys in Phase 2 had a completion rate of $38 \%$. Another factor that appeared to increase willingness to participate was having interviews conducted prior

\footnotetext{
${ }^{10}$ Leonard, Jerry. NMFS Northwest Fish. Sci. Cent., Seattle, Wash. Personal commun. 22 Feb. 2016.
}

to the start of the fishing season, when owners had more time available. Interviews conducted in the off season resulted in higher completion rates than those conducted once the busy fishing season was underway.

In 2012, average characteristics of both owners and vessels illustrate that the owners are highly experienced with over 30 years in the industry. Owners of small vessels are very engaged in daily operations as $90 \%$ captain their own vessel. For large vessel owners, $64 \%$ are captains of their own vessel. In contrast, the study conducted in 2000 found that a larger share of owners of large vessels in Northern California operated their own vessels $(100 \%)$ and a smaller share of owners of large vessels in Southern California operated their vessels $(42 \%){ }^{11}$ For small/medium vessels, between $84 \%$ and $100 \%$ were operated in 2000 by the owner in both areas of the state, which is not too different from the $90 \%$ average in 2012 for boats under $50 \mathrm{ft}$. The 2012 results show that small-vessel owners own one boat on average, and large-vessel owners own about two boats on average. In 2000, primarily only owners of large vessels in Southern California owned more than one vessel (58\%).

In 2000 , the average crew size for large vessels varied between 1.2 fulltime crew in Northern California, and 4.3 full-time crew in Southern California. By 2013, this average was 3.6 crew statewide for large vessels. For small and medium-sized vessels in 2000 , the range was from 0.2 full-time crew (small, Southern California) to 8.9 (small, Northern California). In 2012, the small vessel category had 1.9 crew on average.

Owners of large vessels in 2012 obtain $80 \%$ of their revenues on average from recreational fishing trips (Table

\footnotetext{
${ }^{11}$ In the cost and earnings survey conducted in 2000, the strata included Northern and Southern California, and vessels were classified as small, medium, or large. Large vessels were defined as $50 \mathrm{ft}$ or larger $(15.24 \mathrm{~m})$, similar to the current study's definition of large vessels. However, results were not aggregated across strata, so it is not possible to make a one-to-one comparison to the same categories as in the current study.
}

$3)$. For large vessels in Northern California this was an increase since 2000 , when they earned $74 \%$ of their vessel-based revenues from recreational angling trips, but a decrease for large vessels in Southern California where the percentage was $87 \%$.

Ticket sales in 2012 for recreational fishing account for the largest share of revenues regardless of vessel size. However, there is a difference in large vs. small vessels in terms of what other sources of revenue are important to their operations. Small vessels are more likely to have an additional income stream related to commercial fishing relative to large vessels, and large vessels have a significant source of revenue from non-fishing related recreational trips. Overall, this diversity in revenue streams probably helps owners and crew in terms of financial stability over the year and may help them to compensate for seasonal downturns in recreational fishing activity. Overall, CPFV vessels in 2012 had average net revenues of $\$ 42,000$.

The largest average expenditure categories in 2012 were payroll for crew $(\$ 69,000)$ and fuel costs $(\$ 65,000)$ for all vessel size categories. In 2000, similar patterns were observed across most of the state for both large, medium, and small vessels. In a few cases, fuel costs were slightly higher than payroll costs, but together these two categories made up a large share of overall expenditures.

An issue causing concern among CPFV owners in 2012 was government fisheries regulations. Over $70 \%$ responded to this question stating that this was a very challenging issue for their business. The survey did not go into specifics about which type of regulations were more difficult, other than to include marine protected areas as an example of regulations. Given the recent establishment of marine protected areas off the California coast, this issue may have been forefront in the minds of owners. Prior to the finalization of the regulations governing marine protected areas, there was a lot of uncertainty among anglers and the public over what areas were actu- 
ally open to recreational fishing and what restrictions might be on the horizon. This uncertainty may have been the reason that fisheries regulations were listed as a top concern among the CPFV owners and operators. More research is needed to investigate specifically how the establishment of MPA's will affect the CPFV industry in future years.

The study was designed to provide a concise, descriptive overview of the survey results. Future analysis on the survey results will look into more comparative results, such as the differences in vessels located in Northern California vs. Southern California to see whether or not the differences in fisheries across the state geographically translate into differences in the financial profile of the industry. The survey results can also be used to estimate the economic contributions of the industry to the economy of California in terms of jobs supported and contributions to the state's gross domestic product. Finally, future research should use the results of this study in California to investigate the differences or similarities facing the for-hire industry in the different regions of the country, using the other for-hire surveys recently conducted by NMFS or its partners.

\section{Literature Cited}

Hutt, C., and G. Silva. 2015. The economics of Atlantic highly migratory species for-hire fishing trips, July-November 2013. U.S. Dep. Commer., NOAA Tech, Memo. NMFS OSF4, $34 \mathrm{p}$. (online at http://spo.nmfs.noaa.gov/ tm/TM147.pdf).

Leonard, J. 2016. Washington and Oregon charter vessel survey: methodology and results. U.S.
Dept. Commer., NOAA Tech. Memo. NMFSNWFSC-134. (doi:10.7289/V5/TM-NWFSC134).

Liese C., and D. Carter. 2011. Collecting economic data from the for-hire fishing sector: Lessons from a cost and earnings survey of the southeast U.S. charter boat industry. In T. D. Beard, Jr., R. Arlinghaus, and S. G. Sutton (Editors), The angler in the environment: social, economic, biological, and ethical dimensions. Proc. Fifth World Recreational Fish. Conf., p. 279-292. Am. Fish. Soc., Symp. 75, Bethesda, Md

NMFS. 2014. Fisheries economics of the United States, 2012. U.S. Dep. Commer., NOAA Tech. Memo. NMFS-F/SPO-137, 175 p. (online at https://www.st.nmfs.noaa.gov/economics/publications/feus/fisheries_economics_ 2014/index).

Savolainen, M. A., R. H. Caffey, and R. F. Kazmierczak. 2011. The recreational for-hire sector in the U.S. Gulf of Mexico: structural and economic observations from the third decadal survey. In Proc. Gulf Caribb. Fish. Instit., Puerto Morelos, Mex. 64:102-113.

Stata Software/MP 14.1 for Mac. Oct 2015 StataCorp LP. 4905 Lakeway Drive. College Station, TX. 